this wil focus the image on to the slit of the 30 -feet spectroheliograph or that of the Littrow spectrograph; both these instruments will be underground, and will therefore be preserved at a fairly even temperature.

To provent its distortion, each mirror is to be 12 inches thick, and will be silvered on both sides, and, if necessary, heated on the back by reflected or direct sunlight. An electric motor will drive the photographic plate across the secondary slit of the spectroheliograph, and will by means of a vertical shaft impart a synchronous motion to the I 2 -inch len., and hence to the sun's image.

The Littrow spectrograph is to be fitted with an 8-inch plane grating, and will be employed in the study of the solar rotation and in the photography of sun-spot spectra.

Tile Recent Large Group of Sun-srots.-Another large group of sun-spots visible to the naked eye-of which the solar maximum through which we have just passed has furnished an abnormal number-was observed during the former half of the present month.

The first signs of this group appeared on February 6 , when twc small nuclei were seen on the eastern limb about $15^{\circ}$ south of the equator, and these were followed by two similar spots on February 8 . On February 9 a larger spot brought up the rear of the group, which then contained a large number of small umbra. In London,

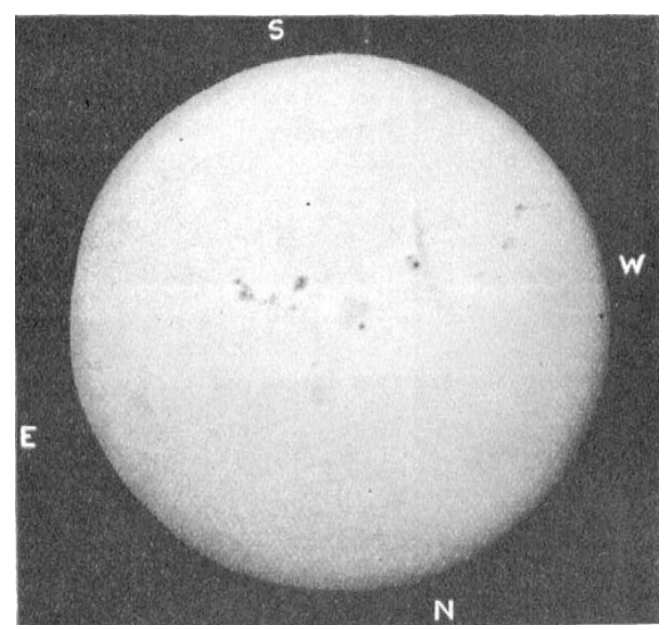

Photograph of sun taken ch. $47 \mathrm{~m}$. February 11, 1907.

bad weather prevented the daily observation of the development of the group, but on February in it was easily visible to the naked eye, and was seen to have developed a second fairly large spot at its preceding extremity. The accompanying reproduction is from a photograph taken at oh. $47 \mathrm{~m}$. on that date, and it may be seen that the preceding spot was then the largest in the group, and had a peculiar kidney-like shape. The total affected area was then roughly rectangular, with a length of about ${ }_{115} 5,000$ miles and a breadth of about 55,000 miles. Naked-eye observations of two groups were possible on February it. The larger group formed a striking spectacle on the western limb on February 18 , but had disappeared from view when the sun was observed on the following day.

The Spectroscopic Binari $\lambda$ Andromede.-From a number of spectrograms of $\lambda$ Andromedx, taken with the Mills spectrograph, $1897-8-9$, a set of elements for the orbit of the binary has been computed by Mr. Burns, of the Lick Observatory. On comparing these elements with those determined from more recent spectrograms, taken with the re-mounted Mills spectrograph, it is seen that there are material differences which can only be reasonably accounted for by the supposition that the orbit itself has been modified. The discrepancy, if established, will probably be found to be due to a third body in the system if this star (Lick Observatory Bulletin, No. Ios).

$$
\text { No. I } 948 \text {, VOL. 75] }
$$

THE GROWTI OF MICRO-ORGANISMS.

THE author, early in the past year, began to make experiments on the origin-of-life question, with various saline solutions containing ammoniacal salts. After a time he found the best results were to be obtained with one or other of two solutions, one of which contained small quantities of sodium silicate, ammonium phosphate, and dilute phosphoric acid in distilled water, and the other a simple solution of sodium silicate with liquor ferri pernitratis in distilled water. It was found, also, that with the use of these saline solutions exposure of the experimental vessels to diffuse daylight, with even a mean temperature of only $60^{\circ} \mathrm{F}$. to $65^{\circ} \mathrm{F}$., favoured the appearance of microorganisms quite as much as, or even more than, darkness associated with an incubator temperature of $95^{\circ} \mathrm{F}$.

The solutions were placed in previously superheated tubes, which, after being hermetically sealed, were heated aggain in a calcium chloride bath to $239^{\circ} \mathrm{F}$. ( $115^{\circ} \mathrm{C}$.), $248^{\circ} \mathrm{F}, 257^{\circ} \mathrm{F}$, or $266^{\circ} \mathrm{F}$. ( $130^{\circ} \mathrm{C}$.), for ten to twenty minutes. In all these tubes, after the process of heating, a small deposit, either of silica alone or of silicate of iron, was thrown down. The tubes were subsequently exposed either to diffuse daylight or else in the incubatcr, and mostly for periods varying from five weeks to four months. When opened, the tubes vere found to contain, in varying abundance, one or more kinds of microorganisms, photographs of which were shown.

One point of much interest in connection with these expcriments is the fact that no carbon was ostensibly contained in the solutions, though its close chemical ally, silicon, was always present.

It had previously been determined that such solutions proved excellent nourishing media for the growth of microcrsanisms, and this fact led to trials whether any evidence was to be obtained tending to show that such solutions could also actually engender living units. On examination of the contents of the tubes after their prolonged periods of exposure to light or in the incubator, the organisms were always found, after cureful search, on or within the substance of the flakes of silica, while the fluid above romained perfectly clear.

Many organic compounds have been discovered by chemists in which silicon wholly or in part replaces carbon. and it is contended that there is good primâa facie evidence from these experiments tending to show that silicon is capable of entering into the composition of protoplasm itself - that is, wholly or in part taking the place of carbon.

In regard to the major question, concerning the origin of life itself, the facts to be borne in mind are these :If a few hours after the heating of the tubes one or more of them be opened as "control" experiments and the sediment carefully examined, no organisms of any kind are to be found, but, after suitable periods of exposure, organisms may be found, in more or less abundance, in the sediment taken from other similar tubes. Here, then, is evidence that the organisms are living; they have appeared and multiplied within sealed tubes, though at carlier dates none is to be found.

Then again, it is important to bear in mind (I) that, apart from "spores" of bacilli, no micro-organisms can resist an exposure of two or three minutes in boiling water, this being lethal for bacteria, vibriones, micrococci, torula, and moulds; and (2) that all ordinary spores of bacilli are killed by a similar exposure for a minute or two to $115^{\circ} \mathrm{C}$. $\left(239^{\circ} \mathrm{F}.\right)$.

It is concluded, therefore, that the bacteria, bacilli, vibriones, micrococci, torulæ, and moulds which have been taken from hermetically-sealed tubes previously heated to $115^{\circ} \mathrm{C}$., $120^{\circ} \mathrm{C}$, $125^{\circ} \mathrm{C}$., and $130^{\circ} \mathrm{C}$. for ten to twenty minutes must have been engendered de novo within these vessels.

The organisms that arise de novo are presumed by the author to assume well-known forms, for precisely the same reason that the various representatives of the crystalline world, when they originate, invariably fall into their own specific shapes, and with surfaces always inclined to one 1 "On the de-novo Origin of Bacteria, Bacilli, Vibriones, Micrococci, Torula and Moulds in certain previously superbeat $t$ d Saline Solutions contained within hermetically sealed Tubes." By Dr. H. Charlton Bastian, F.R.S. Read before the Royal Medical and Chirurgical Society on January 22. 
another at angles that never vary for each particular species of crystal. The forms in each set of cases-in organisms and in crystals alike-may be regarded as the necessary resultants of the molecular constitution of their initial units in the particular media and surroundings in which they occur.

\section{PROPERTIES OF ALLOIS.}

THE rescarch described in the report was carried out by the authors with the cooperalion of the Broughton Copper Co., Manchester, and the British Aluminium Co.,

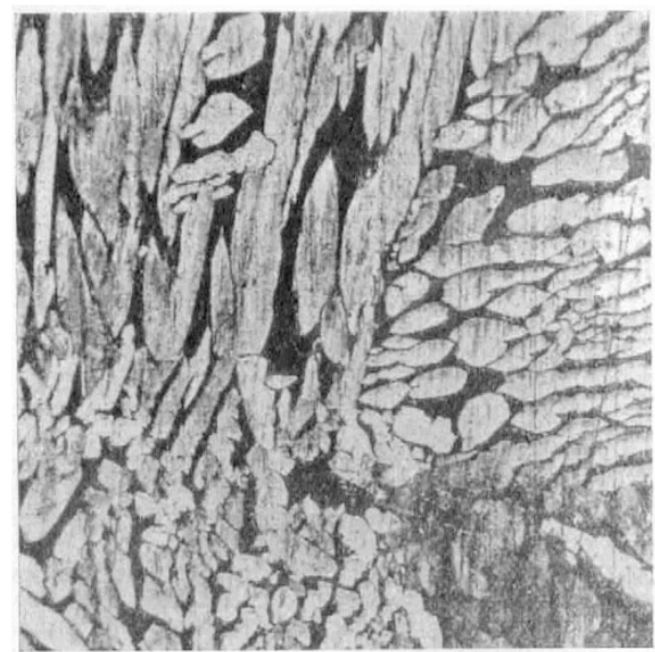

Rolled.

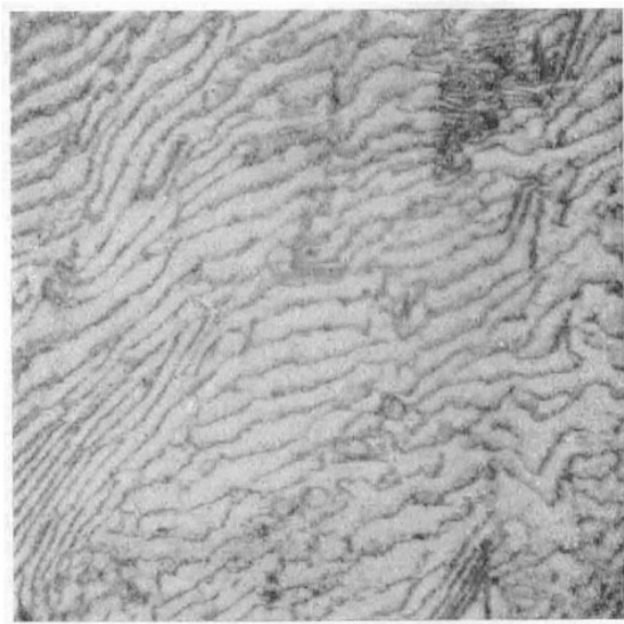

chiefly those very rich in copper. At this end of the series the limit of serviceable alloys must be placed at II per cent. At the other end of the series the limit is cven smaller. Among the specifically light alloys rich in aluminium the limit is probably not higher than 4 per cent. of copper. Belween ir per cent. and 96 per cent. of aluminium (exclusive) the alloys do not appear to be of any practical promise.

(b) But if the range of serviccable alloys is narrow, their quality is cerlainly high in several instances. This statement holds for certain of the rich copper alloys containing between 7 per cent. and so per cent of aluminium. It is not going two far to say that in certain respects the

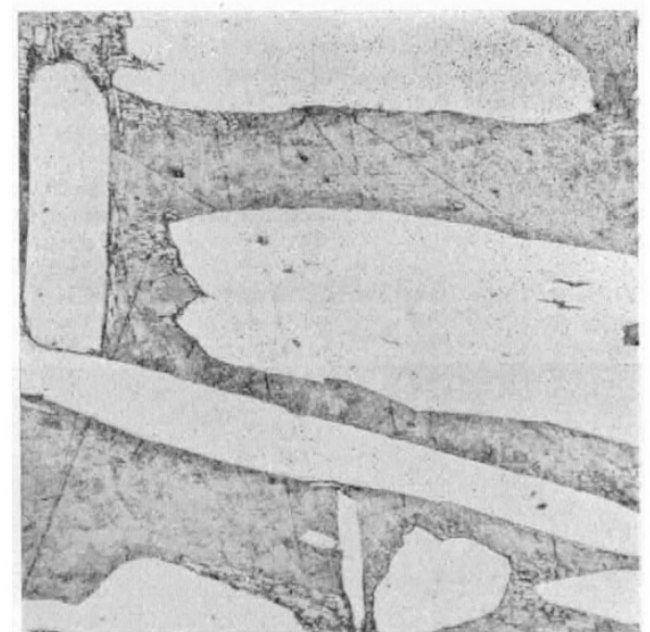

After pr. longed annealing.

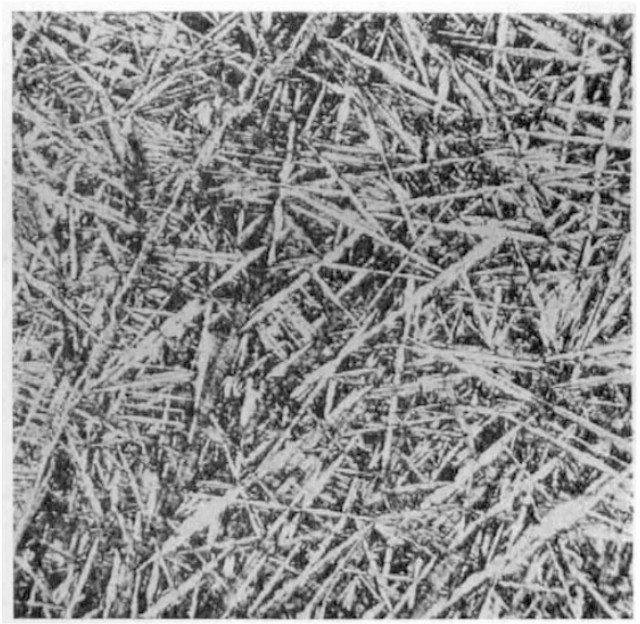

Structures of an alloy cont ining $\left\{\begin{array}{c}90^{\circ} \circ 6 \text { per cent. of copper. } \\ 9.90, " \text { aluminium. }\end{array}\right.$ Magnification I 50 diamet ars."

Milton, who furnished respectively the best commercial copp $\times$ r and aluminium for making the alloys, undertcok the rolling and drawing of the materials, and made special castings where necessary.

The salient points of the report are stated as follows :-

(a) The number of alloys that have been found of any industrial and technical promise is small. Such alloys are

1 Abstract of the Eighth Report to the Alloys Research Committee : On the Properties of Alloys of Aluminium and Copper. By Prof. H. C. H. Car1 inter and Mr. C. A. Edwards, of the National Physical Laboratory. Kead at the Institution of Mechanical Engineers on January 18.

NO. 1948, VOL. 75] best of them equal, and even surpass, high-quality steels of the same general character.

The following summary refers only to the rich copper alloys :-

(c) Four features of the results of the tensile stress tests of outstanding interest merit a special comment.

(I) In view of the doubt which exists at the present time as to whether copper and its alloys possess true yield-points, it is important to record that from o.I per cent. to 9 per cent. of aluminium the alloys possess clearly marked yield-points. 